\title{
O USO DE GEOINDICADORES EM PAISAGEM RURAL: SUBSÍDIOS À ANÁLISE DAS MUDANÇAS MORFOLÓGICAS ANTROPOGÊNICAS DA BACIA DO CÓRREGO DO CAVALHEIRO - ANALÂNDIA (SP)
}

\author{
Leandro de Godoi Pinton ${ }^{1}$ \\ Cenira Maria Lupinacci da Cunha ${ }^{2}$
}

Resumo: A criação de metodologias nos estudos da Antropogeomorfologia tem contribuído para a mensuração das mudanças morfológicas induzidas pelo homem. Neste contexto, a sistematização de geoindicadores permite leituras quantitativas de diversos parâmetros geomorfológicos. A diversidade de sistemas ambientais e a maior intensidade das ações antrópicas sugerem o estabelecimento de geoindicadores mais específicos. Assim, o presente artigo teve como objetivo analisar a formulação de morfologias antropogênicas vinculadas às mudanças do uso da terra em área rural e, a partir dessa análise, discutir geoindicadores que permitam realizar a quantificação de formas do relevo que indicam processos geomorfológicos dinamizados pela ação antrópica. A disposição natural da bacia do Córrego do Cavalheiro - Analândia (SP), na transição entre as Cuestas Areníticas-Basálticas e a Depressão Periférica Paulista, atrelada a uso da terra essencialmente rural condicionam o seu enquadramento na referida perspectiva. A análise correlativa entre os dados obtidos com as cartas de uso da terra e geomorfológicas numa série histórica de 51 anos permitiu a definição de geoindicadores, que se mostraram eficazes no monitoramento de feições derivadas do antropogênico, constituindo-se em lista passível de uso em sistemas com dinâmica natural e de uso da terra análoga a área de estudo.

Palavras-chave: Antropogeomorfologia; Geoindicadores; Cartografia Geomorfológica; Paisagem Rural.

THE USE OF GEOINDICATORS IN THE RURAL LANDSCAPE: CONTRIBUTIONS FOR THE ANALYSIS OF THE ANTHROPOGENIC MORPHOLOGICAL CHANGES IN CAVALHEIRO STREAM BASIN - ANALÂNDIA CITY (SP).

Abstract: The elaboration of new methodologies in Anthropogeomorphology has contributed to measure the morphological changes induced by the human being. In this context, the geoindicators systematization allows the quantitative reading of different geomorphological parameters. The diversity of environmental systems and the higher intensity of anthropic actions suggest the need of more specific geoindicators. Thus, this study aimed to analyze the establishment of anthropogenic morphologies associated with the changes regarding the land use in rural areas, and drawing upon this analysis, discuss geoindicators which allow the quantification of landforms that indicate geomorphlogical processes accelerated by the

1. Doutorando em Geografia, Universidade Estadual Paulista - UNESP, Rio Claro-SP (Igpgeo@yahoo.com.br).

2. Profa. Dra . do Departamento de Planejamento Territorial e Geoprocessamento (DEPLAN), Universidade Estadual Paulista - UNESP, Rio Claro-SP (cenira@rc.unesp.br). 
anthropic action. The natural disposition of Cavalheiro Stream Basin - Analândia city (SP), in the transition between Basalt-Sandstone Cuestas and São Paulo State Peripheral Depression, along with the essentially rural land use fundamented its classification under such perspective. The correlation analysis of the data obtained from geomorphological and land use maps over a 51-year period allowed the creation of geoindicators to monitor the anthropogenic features, yielding a list to be used in systems with natural dynamics and land use similar to the studied area.

Key words: Anthropogeomorphology; Geoindicadors; Geomorphologic Cartography, Rural Landscape.

\section{INTRODUÇÃO}

A inserção das interferências antrópicas como agente modelador do relevo é uma consideração relativamente recente na literatura geomorfológica (NIR, 1983; GOUDIE, 1993; HAFF, 2001; SZABÓ, 2010), salvo algumas exceções destacadas por Goudie (1993) do final do século XIX e início do XX nas obras de Marsh (1864), McGee (1911), Shaler (1912), Gilbert (1917) e Sherlock (1922).

A premissa verificada na década de 70 sobre a conscientização ambiental numa escala global, acrescida da evidente influência humana no funcionamento dos sistemas geomorfológicos, forneceu as condições favoráveis para o desenvolvimento da Antropogeomorfologia, sendo o trabalho de Nir (1983) o precursor nesta abordagem.

No Brasil, Rodrigues (1997) foi responsável pela introdução e aplicação de uma metodologia fundamentada nas proposições de Nir (1983). De acordo com tal autora, é necessário o reconhecimento de sistemas geomorfológicos em seus diversos estágios de intervenção antrópica (período de pré-perturbação, equivalente a fase anterior à intervenção antrópica; períodos de perturbação ativa e pós-perturbação, que representam a sequência de intervenções nas formas e materiais superficiais pela atividade antrópica) para que seja possível identificar unidades espaciais em suas combinações de morfologia original e antropogênica.

De acordo com Rodrigues (2005, p. 104), a morfologia original

[...] é a que não sofreu intervençãodireta nas formas originais, ou seja, os sistemas geomorfológicos podem tersido objeto de interferências importantes do ponto de vista dos processos, comono caso da ação do desmatamento, mas não sofreram remanejamentos diretos significativos 
de material como aqueles que ocorrem em áreas com aragem, pastagem intensiva e uso de trator (superfícies agrícolas) ou cortes, aterros esubstituição por materiais tecnogênicos (superfícies urbanas).

Enquanto que a morfologia antropogênica é aquela que se origina induzida pela interferência antrópica como ação geomorfológica, “[...] ação essa que pode: modificarpropriedades e localização dos materiais superficiais; intervir em vetores, taxas e balanços dos processos e gerar, de forma direta e indireta, outra morfologia" (RODRIGUES, 2005, p. 101).

Pinton (2011), ao considerar as orientações básicas de Rodrigues (1997, 2005), realizou estudos da Antropogeomorfologia em bacia hidrográfica sob forte intervenção de atividades antrópicas relacionadas, especialmente, ao cultivo da cana-de-açúcar. Assim, a partir da correlação dos dados obtidos com as cartas geomorfológicas e de uso da terra de distintos cenários em escala de detalhe da sua área de estudo, o referido autor constatou que a introdução do cultivo de cana-de-açúcar deu origem às morfologias antropogênicas, as quais se encontravam diretamente relacionadas com a dinamização dos processos erosivos lineares e alterações nas rupturas topográficas e formas de vertente.

A suposta dinamização foi investigada por meio de uma avaliação qualitativa das feições erosivas, considerando avanços em seus estágios evolutivos e, ainda, a partir da averiguação da quantidade das mesmas segundo o uso da terra associado ao longo do seu período de análise. Todavia, tal procedimento não forneceu condições para a mensuração da taxa de evolução destes processos derivados ou não de ações antrópicas.

Recentemente, alguns estudos na área da Antropogeomorfologia passaram a empregar propostas metodológicas que podem elucidar tal investigação. Rodrigues (2010) desenvolveu um quadro de indicadores que consistem em parâmetros para avaliação das mudanças ambientais e efeitos da intervenção antrópica do urbano em sistemas hidrogeomorfológicos do meio tropical úmido, para escalas regionais e de detalhe, considerando intervalos temporais de aproximadamente cem anos.

O quadro foi construído por Rodrigues (2010, p. 118) com base em indicadores morfológicos, de materiais superficiais e de,

[...] está estruturado em parâmetros e, por tipo (formas, materiais e processos, antropogênicos ou originais), por escala e por sistema 
geomorfológico, apresentando-se as respectivas unidades de medida e intervalos temporais recomendados para o monitoramento. Trata-se de lista metodologicamente construída para leituras quantitativas isoladas ou correlacionadas e passíveis de interpretações na perspectiva da ciência geomorfológica.

A sistematização deste quadro foi inspirada na proposta dos geoindicadores do grupo de trabalho da Comissão de Ciências Geológicas para o Planejamento Ambiental COGEOENVIRONMENT - da União Internacional de Ciências Geológicas - IUGS. Coltrinari e McCall (1995) evidenciaram a existência de algumas dificuldades inerentes às tentativas de avanços em estudos que visavam ir além da simples enumeração dos geoindicadores e seus parâmetros espaço-temporais. Nesta mesma conjuntura, Berger e lams (1996 apud COLTRINARI, 2002) evidenciaram que a

[...] diversidade dos ambientes terrestres e as múltiplas formas, magnitudes e duração das pressões exercidas pela intervenção antrópica sugerem [...] a necessidade permanente de revisões e refinamento da lista original e um conhecimento mais profundo da dinâmica dos processos a serem monitorados.

Coltrinari (2002) salienta que tais dificuldades são acentuadas na zona tropical úmida devido a falta de conhecimento de sua complexidade, inexistência de bancos de dados e maior intensidade da pressão das intervenções antrópicas sobre o ambiente natural, especialmente dos grandes aglomerados urbano-industriais. Neste contexto, alguns esforços foram realizados por Coltrinari (2002) e Gupta (2002). De forma geral, nota-se que tanto estas propostas de geoindicadores, quanto os indicadores de Rodrigues (2010) concentraram esforços para identificar e quantificar os efeitos das ações antrópicas derivadas da expansão urbana.

Apesar disso, ambas reforçam os princípios apresentados pelo grupo de trabalho da COGEOENVIRONMENT no que tange as possibilidades de formulação de geoindicadores mais específicos a dimensões espaço-temporais diferenciadas tanto do ponto de vista natural, quanto da diversidade das intervenções antrópicas.

As morfologias antropogênicas estabelecidas em sistemas ambientais atrelados ao uso da terra essencialmente rural são comuns no cenário brasileiro, pois esse se constitui em típico país exportador de produtos básicos e semimanufaturados de baixo valor agregado (BRASIL, 
2014). Neste viés, verifica-se a necessidade de estabelecer geoindicadores que possibilitem avaliar as implicações das atividades antrópicas no rural.

Assim, o presente artigo teve como objetivo analisar a formulação de morfologias antropogênicas vinculadas às mudanças do uso da terra em área rural e, a partir dessa análise, discutir geoindicadores que possibilitem quantificar as formas do relevo que indicam processos geomorfológicos dinamizados pela ação antrópica.

A bacia do Córrego do Cavalheiro - Analândia (SP) foi selecionada como área de estudo em razão de seu elevado potencial na inserção de tal perspectiva. Além da diversidade natural derivada de sua disposição na transição entre as Cuestas Areníticas-Basálticas e a Depressão Periférica Paulista, essa apresenta uma evolução temporal do uso da terra associada às atividades agropecuárias (PINTON, 2011).

\section{CARACTERIZAÇÃO DA ÁREA DE ESTUDO}

A bacia hidrográfica do Córrego do Cavalheiro localiza-se no setor centro-leste do Estado de São Paulo, no município de Analândia, entre as coordenadas geográficas de $22^{\circ} 05^{\prime} 36^{\prime \prime}$ e

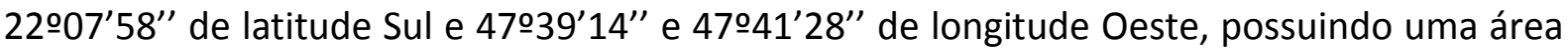
de $9,9 \mathrm{~km}^{2}$ (Figura 1).

O Córrego do Cavalheiro é afluente da margem esquerda do rio Corumbataí e constitui-se em uma das áreas de nascentes deste rio, o qual possui grande importância regional devido ao seu potencial hídrico para abastecimento dos municípios de Analândia, Corumbataí, Rio Claro e Piracicaba.

A morfogênese responsável pelos compartimentos geomorfológicos da bacia do Córrego do Cavalheiro desenvolve-se sobre litologias cuja deposição ocorreu desde o período Mesozóico ao Cenozóico. De acordo com São Paulo (1984), datadas do Mesozóico, encontram-se as formações pertencentes ao Grupo São Bento - Pirambóia, Botucatu e Serra Geral - e, ainda, a formação Itaqueri. É necessário destacar que não há um consenso para a datação da formação Itaqueri, pois essa já foi considerada inicialmente como série basal do Grupo Bauru e, atualmente, alguns autores indicam que sua formação pode ser posterior ao 
referido grupo (MELO, 1995). No que se refere às litologias datadas do Cenozóico, encontrase apenas a formação Santa Rita do Passa Quatro (SÃO PAULO, 1984).

Sobre estas condições litológicas, segundo Koffler (1992), verificam-se as seguintes classes de solos: neossolos, nitossolos, latossolos e argissolos.

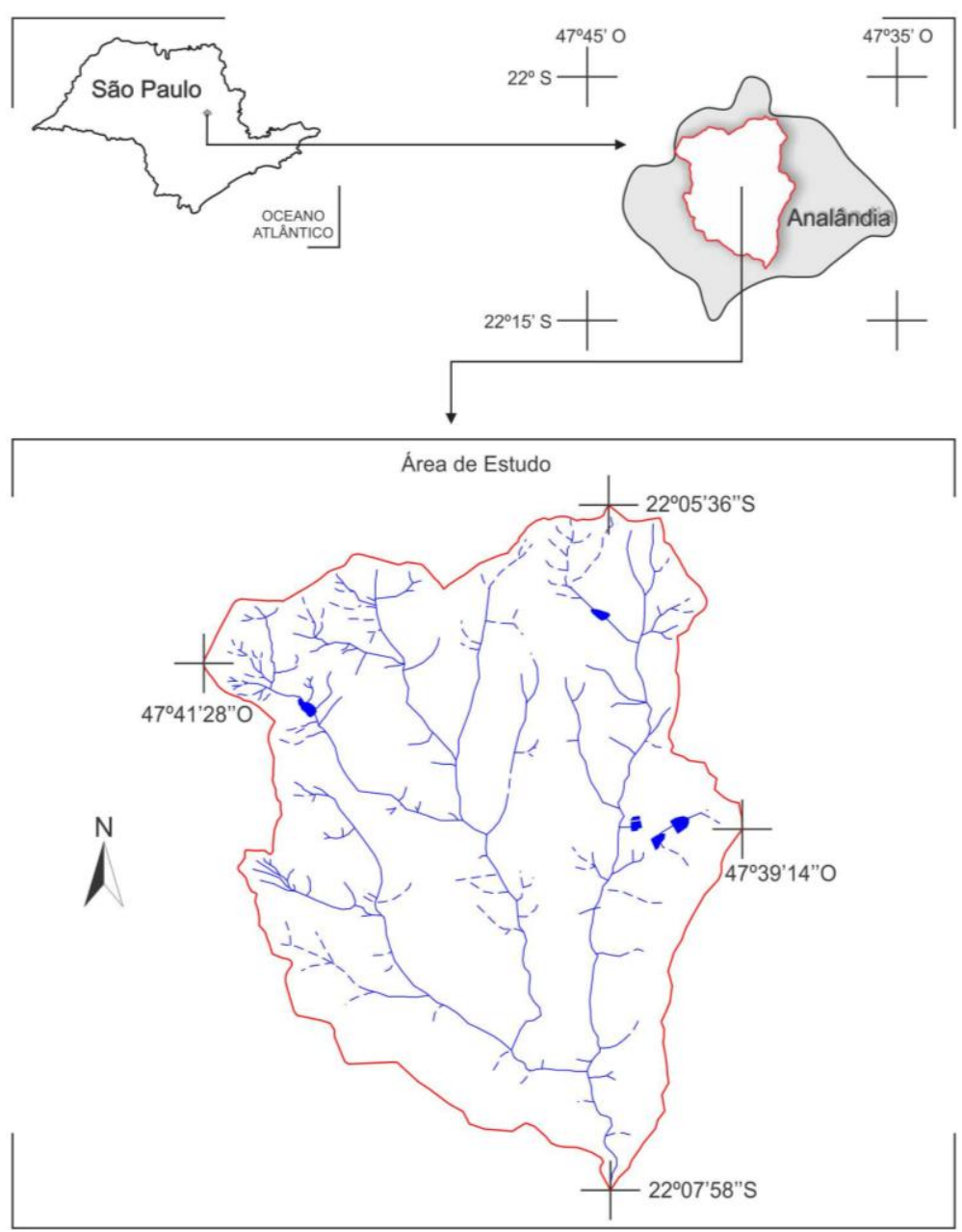

Figura 1: Localização da Bacia do Córrego do Cavalheiro no Estado de São Paulo e Município (sem escala). Elaborado pelos autores (2015)

Os aspectos climáticos que influenciam nos processos de formação destes solos se relacionam a subunidade intitulada de Centro-Norte da classificação climática proposta por Monteiro (1973) para o território paulista. Esta subunidade integra-se aos climas regionais tropicais alternadamente secos e úmidos, os quais fazem parte dos climas zonais controlados por massas equatoriais e tropicais. 


\section{MATERIAL E MÉTODO}

A orientação metodológica do presente artigo teve respaldo nos princípios que concernem à Teoria Geral dos Sistemas aplicados à ciência geográfica (CHRISTOFOLETTI, 1979), sendo que esses ainda integram a abordagem da Antropogeomorfologia (NIR, 1983; RODRIGUES, 2005).

A escolha de uma bacia hidrográfica como área de estudo justifica o uso da abordagem sistêmica quanto ao critério funcional, pois essa se constitui em um sistema aberto que recebe (input) e perde (output) energia e massa.

Quanto ao critério da complexidade estrutural, utilizou-se a concepção dos sistemas controlados, pois esses consideram o homem como elemento que "[...] pode intervir para produzir modificações na distribuição de matéria e energia dentro dos sistemas em sequência e, consequentemente, influenciar nas formas que com ele estão relacionadas" (CHRISTOFOLETTI, 1979, p. 19).

Este aspecto do sistema foi avaliado por meio de uma análise correlativa entre os dados obtidos com as cartas de uso da terra e geomorfológicas dos cenários de 1962, 1978, 1988, 2009 e 2013 da bacia do Córrego do Cavalheiro. Os referidos dados proporcionaram a identificação das implicações da dinâmica do uso da terra, vinculada às ações antrópicas, sobre a distribuição de matéria e energia, culminando em uma morfologia antropogênica. Ademais, esses permitiram a definição dos geoindicadores, estabelecidos com base na configuração espacial das feições geomorfológicas que denotam a atuação de processos morfogenéticos susceptíveis a intensas mudanças numa escala de tempo histórica.

Neste viés, a cartografia geomorfológica retrospectiva permitiu a quantificação dos parâmetros extensão (metros) e quantidade (número total) dos geoindicadores, fornecendo informações sobre a sua evolução num período de 51 anos.

A elaboração das cartas geomorfológicas foi realizada segundo a proposta de Tricart (1965), utilizando-se pares estereoscópicos de fotografias; mapeamentos geológicos; base cartográfica e trabalhos de campo para a reambulação dos dados mapeados em 2013. Tais documentos ainda consideraram alguns símbolos da proposta de Verstappen e Zuidan (1975). 
O referido conjunto de fotografias aéreas também serviu de base para o mapeamento do uso da terra, realizado em meio digital a partir das 4 etapas apresentadas por Cunha e Pinton (2009). Ressalta-se que o desenvolvimento do cenário mais recente, tanto para as feições geomorfológicas quanto para as classes de uso da terra, incorporou a fotointerpretação de imagens tridimensionais geradas pela técnica Anáglifo em meio digital do software StereoPhoto Maker (SOUZA; OLIVEIRA, 2012).

\section{RESULTADOS E DISCUSSÃO}

A dinâmica do uso da terra da bacia do Córrego do Cavalheiro no período analisado foi caracterizada por significativas mudanças em cada cenário (Gráfico 1), com destaque ao comportamento das classes pasto limpo, pasto sujo, silvicultura, cana-de-açúcar e mata.

As áreas ocupadas por pasto limpo se sobressaíram sobre as demais, mesmo com uma diminuição gradual a partir de 1988. Além desta diminuição, constatou-se no cenário seguinte, a diminuição de áreas cobertas por mata, em contrapartida ao surgimento do cultivo da cana-de-açúcar e um exíguo aumento na extensão das áreas com silvicultura e pasto sujo. Em cenário mais recente, houve o aumento na extensão das áreas ocupadas por cana-de-açúcar e silvicultura, bem como recuperação da mata, e consequente diminuição do pasto sujo.

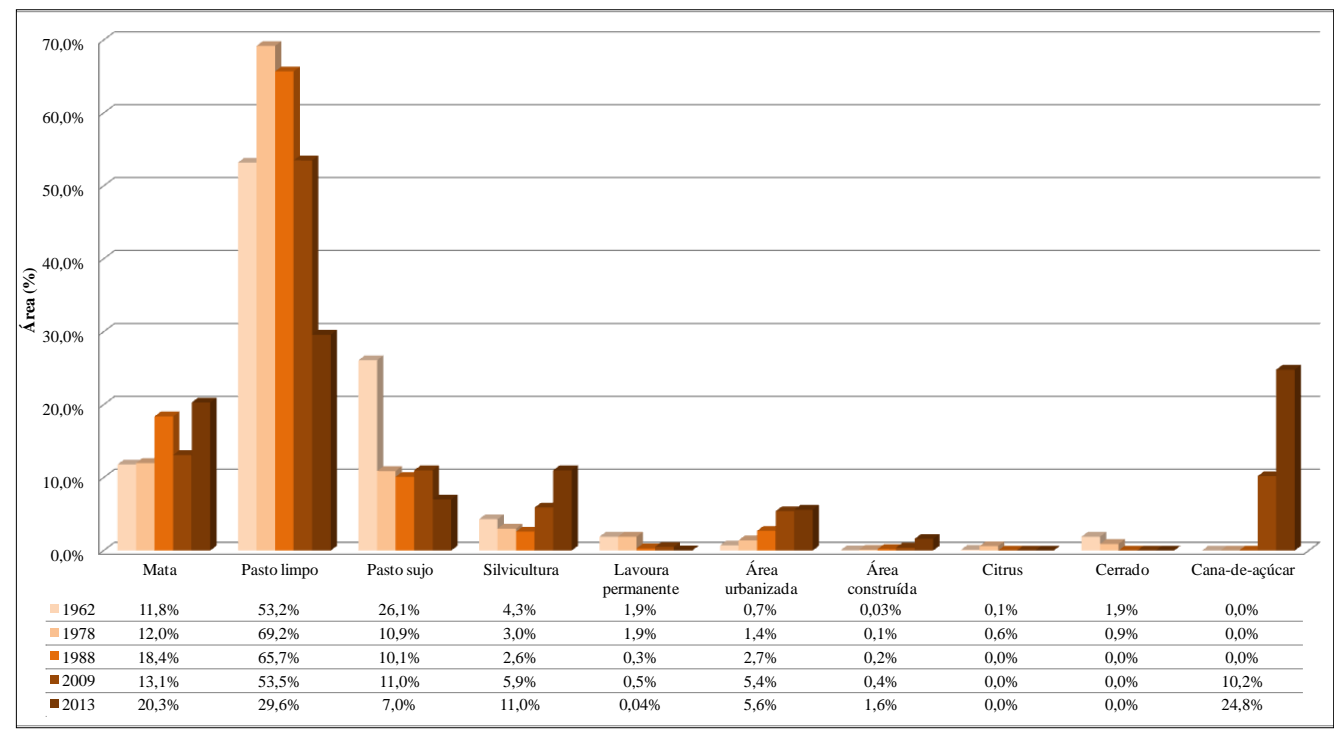

Gráfico 1: Evolução em porcentagem (\%) da área ocupada pelas classes de uso da terra da bacia do Córrego do Cavalheiro - Analândia (SP) no período de 1962 a 2013.

Elaborado pelos autores (2015). 
De forma geral, o manejo realizado ao longo do tempo nas áreas com cana-de-açúcar, silvicultura e pasto limpo envolveu a aplicação de técnicas conservacionistas que conduziram alterações em feições geomorfológicas e, consequentemente, determinaram a constituição de uma morfologia antropogênica.

A maior parte das modificações está relacionada diretamente a dinâmica de formas de caráter denudativo - feições erosivas lineares (sulcos, ravinas e voçorocas), rupturas topográficas e colos topográficos, e também, mas de modo indireto, na organização de feições deposicionais - leques aluviais.

Neste contexto, os geoindicadores da bacia do Córrego do Cavalheiro e suas respectivas propriedades que forneceram subsídios a quantificação de implicações provenientes da ação antropogênica são apresentados no Quadro 1.

As rupturas e os colos topográficos indicam, em um cenário natural, os setores de maior fragilidade dos materiais constituintes do relevo nos quais a ação denudativa tem sido mais eficiente. Tais feições tendem a evoluir a partir de amplas escalas de tempo. Todavia, os desajustes em seus parâmetros numa série histórica pressupõem as mudanças causadas pela ação humana. O referido pressuposto também pode ser identificado no comportamento das feições erosivas lineares, já que a expressividade dessas em curto período de tempo responde de forma direta ou indireta a interferência antrópica na dinâmica dos processos erosivos lineares.

\begin{tabular}{|c|c|c|c|c|}
\hline \multicolumn{2}{|c|}{ Geoindicadores } & Parâmetro & $\begin{array}{l}\text { Unidade } \\
\text { de medida }\end{array}$ & Origem \\
\hline \multirow{5}{*}{$\begin{array}{l}\text { Feições } \\
\text { Erosivas } \\
\text { Lineares }\end{array}$} & \multirow{2}{*}{ Sulcos erosivos } & Extensão & Metros & \multirow{7}{*}{ Denudativa } \\
\hline & & Quantidade & Número total & \\
\hline & Ravinas & Quantidade & Número total & \\
\hline & \multirow{2}{*}{ Voçorocas } & Extensão & Metros & \\
\hline & & Quantidade & Número total & \\
\hline \multicolumn{2}{|c|}{ Rupturas topográficas } & Extensão & Metros & \\
\hline \multicolumn{2}{|c|}{ Colos topográficos } & Quantidade & Número total & \\
\hline \multicolumn{2}{|c|}{ Leques aluviais } & Quantidade & Número total & Deposicional \\
\hline
\end{tabular}

Quadro 1: Geoindicadores e propriedades para quantificação e detalhamento dos processos geomorfológicos da bacia do Córrego do Cavalheiro - Analândia (SP).

Elaborado pelos autores (2015). 
Os leques aluviais, por sua vez, derivam do aumento significativo na carga de materiais no rio, que sobrecarregam a sua dinâmica deposicional na foz. A fonte de abastecimento dos materiais pode ter vínculo com a dinâmica dos processos erosivos lineares ou laminares, os quais se encontram sujeitos a alterações advindas do antrópico.

A análise da prancha de gráficos (Figura 2) permite dimensionar o comportamento dos geoindicadores da área de estudo, conduzido predominantemente pela dinâmica do uso da terra do período de análise.

No período de 1962 a 1978, houve uma diminuição na quantidade das feições erosivas lineares (Figura 2A), com significativa queda no número de sulcos erosivos (redução de 257 feições) e voçorocas (diminuição de 7 feições). Ressalta-se que o comportamento referente à extensão destas feições acompanhou aquele indicado na quantidade (Figura 2B). As ravinas são exceção ao contexto descrito, pois o número total dessas aumentou de 13 em 1962 para 17 em 1978.

A dinâmica de uso da terra da área de estudo neste período, demonstrada no gráfico 1, é marcada pela redução do pasto sujo (26,1\% para $10,9 \%)$ e aumento de $16 \%$ na área ocupada pela classe de uso da terra pasto limpo (53,2\% para $69,2 \%)$. Esse tipo de pastagem tende ao desenvolvimento de medidas conservacionistas no terreno, que possivelmente conduziram ao controle de sulcos erosivos e voçorocas. É notável a influência desta substituição no decréscimo da quantia das referidas feições erosivas lineares, mesmo em áreas caracterizadas por suscetibilidade erosiva perante seus atributos naturais, com destaque a inclinação das vertentes e litologias friáveis.

O sudoeste e sudeste da bacia do Córrego do Cavalheiro se encaixam nesta situação, pois a variação nos tipos de uso da terra foi acompanhada pela contenção de sulcos erosivos, mesmo tendo em vista uma fragilidade decorrente da organização de seus aspectos litológicos e clinográficos (Figura 3). No sudeste, o estabelecimento da citricultura e a duplicação da área urbanizada em 1978 também podem ter auxiliado na diminuição da intensidade destas feições.

O noroeste da área de estudo (Figura 4), apesar de algumas distinções relacionadas à dinâmica do uso da terra e de seus elementos naturais, pode ser enquadrado como similar a 
conjuntura descrita acima. No cenário de 1962, esse setor apresentava sulcos erosivos que seguiam a orientação de um canal pluvial. Todavia, nota-se que tanto os sulcos erosivos quanto o canal pluvial foram eliminados em 1978, sendo substituídos por morfologia antropogênica condizente a terraço agrícola. A verificação do uso da terra nesta área em ambos os cenários indica a manutenção das classes de uso da terra lavoura permanente e silvicultura.

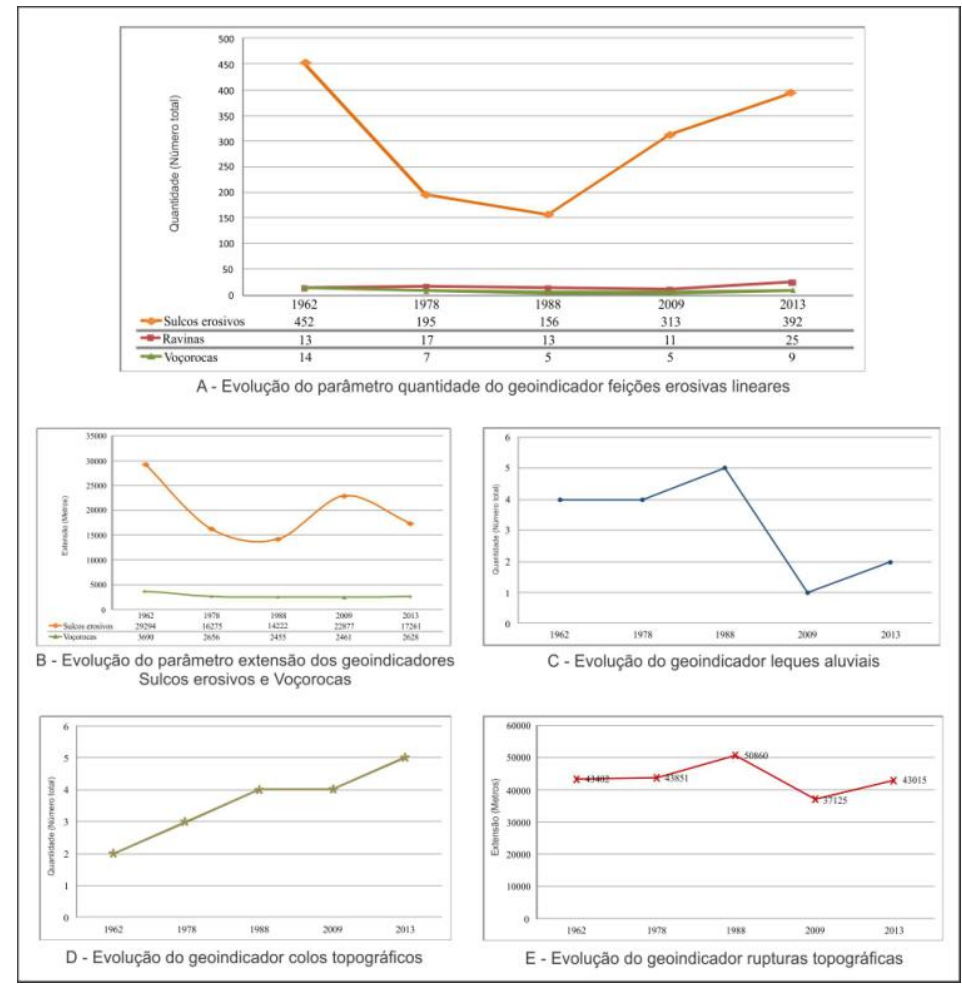

Figura 2: Prancha de gráficos da evolução dos geoindicadores da bacia do Córrego do Cavalheiro - Analândia (SP) no período de 1962 a 2013.

Elaborado pelos autores (2015).

Neste viés, acredita-se que o surgimento de terraços agrícolas corresponda a incorporação de um novo manejo relacionado a tais usos para adequar as intervenções antrópicas a fragilidade local advinda de discordância lito-pedológica e declividade entre 5 a 20\%, com predomínio da faixa de 5 a $12 \%$.

As limitações proeminentes deste terreno ao seu manejo frente aos referidos usos da terra eram evidentes em 1962, pois além dos sulcos erosivos, havia uma voçoroca de grande extensão. No cenário de 1978, após o uso de técnica conservacionista, constatou-se neste local a presença de uma ravina, cuja regressão deixa perceptível a amenização dos processos erosivos lineares. 


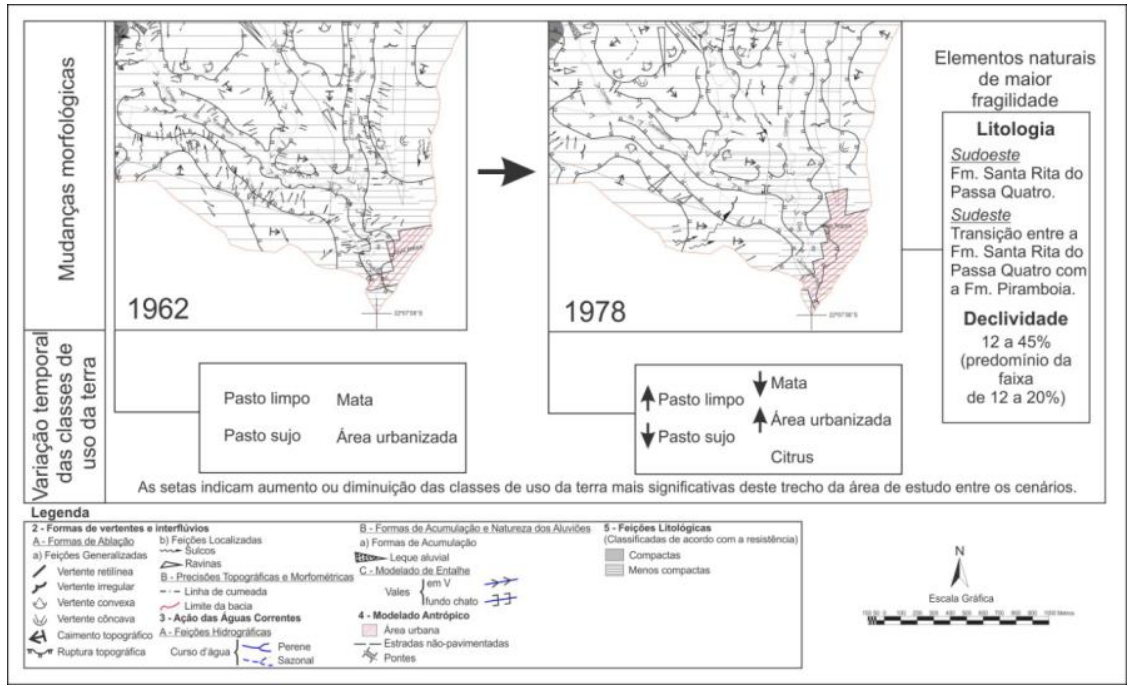

Figura 3: Mudanças morfológicas no geoindicador sulcos erosivos e a variação temporal das classes de uso da terra mais significativas no sudoeste e sudeste da bacia do Córrego do Cavalheiro - Analândia (SP) no período 1962-1978.

Elaborado pelos autores (2015).

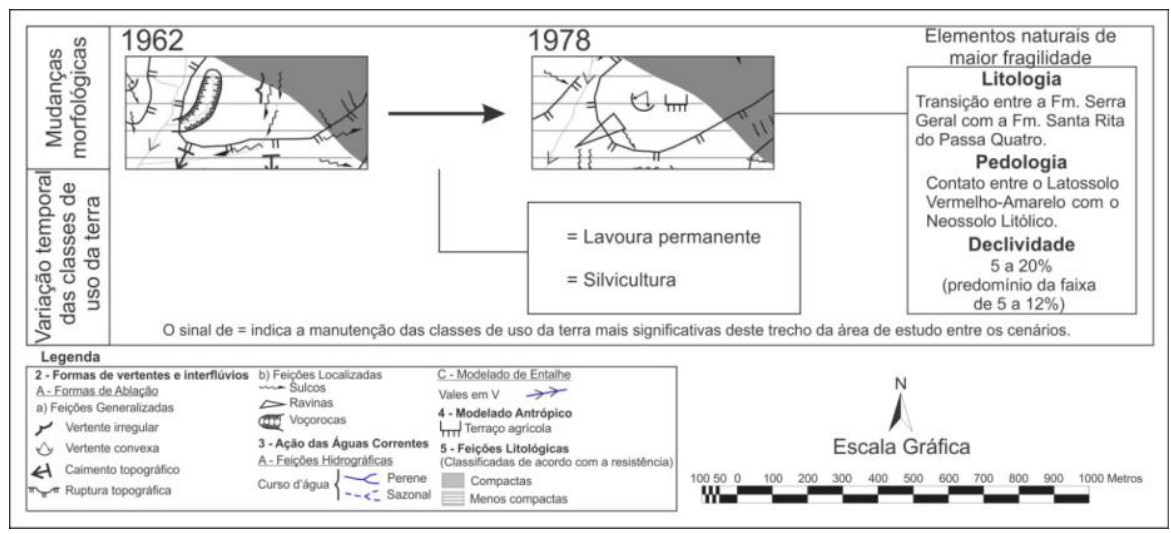

Figura 4: Constituição de morfologia antropogênica e mudanças morfológicas nos geoindicadores sulcos erosivos e voçorocas no noroeste da bacia do Córrego do Cavalheiro - Analândia (SP) no período 1962-1978. Elaborado pelos autores (2015).

Em relação às ravinas, o seu aumento no período 1962 - 1978 esteve atrelado a processos morfogenéticos incitados, aparentemente, pela disposição de determinados elementos naturais, pois a maior parcela dessas foi identificada em áreas compostas por distintos contatos lito-pedológicos e considerável variação de declive. Todavia, não é possível atribuir a exclusiva responsabilidade de sua gênese aos aspectos físicos, já que houve o surgimento de um conjunto de ravinas através da instituição de linhas de escoamento superficial pela organização de classes de uso da terra que se mantiveram no período, referentes a lavoura permanente, pasto sujo e, até mesmo, pasto limpo. 
Em contrapartida a redução verificada no contexto geral das feições vinculadas à erosão linear no intervalo 1962 - 1978, a manutenção na quantia de leques aluviais (Figura 2C) e o aumento na quantia de colos topográficos (Figura 2D) e na extensão das rupturas topográficas (Figura 2E) permitem inferir a ocorrência de um aumento da erosão laminar.

O subsequente aumento na década seguinte (1978 - 1988) nos parâmetros dos geoindicadores leques aluviais, colos e rupturas topográficas e a diminuição das feições erosivas lineares, inclusive as ravinas, indica uma possível dinamização do processo erosivo laminar e diminuição do linear.

O domínio da classe de uso da terra pasto limpo, ocupando $65,7 \%$ da área de estudo, acompanhado do singelo aumento da classe mata (12\% para 18,4\% - Gráfico 1), fornece subsídios a inferência realizada sobre a dinâmica dos referidos processos erosivos. A recomposição da mata ao longo deste período proporcionou a supressão de voçorocas e ravinas, bem como a diminuição de sulcos erosivos. Ressalta-se que a eliminação de ravinas foi favorecida ainda com a substituição da lavoura permanente por pasto limpo.

No entanto, o manejo utilizado na estruturação deste uso da terra não coíbe o desenvolvimento de processos denudativos em áreas caracterizadas por fragilidade litopedológica, já que a significativa extensão das rupturas topográficas no cenário de 1988 foi derivada de gênese e expansão no interior e entorno de parcelas consolidadas com pasto limpo. Assim, acredita-se que os arranjos espaciais que envolvem tal uso favoreceram a exposição dos materiais resultantes das intempéries locais aos processos erosivos laminares.

A única exceção ao contexto descrito foi identificada no sudeste da área de estudo, distinguida por alterações significativas no direcionamento de rupturas topográficas em 1988, as quais estiveram atreladas ao desenvolvimento de morfologia antropogênica vinculada ao uso urbano. A criação de taludes voltados ao nivelamento do terreno foi realizada com o intuito de proporcionar melhor condição para a expansão da área urbana do município, que se manteve de forma gradual nos demais cenários. De acordo com o gráfico 1, houve um aumento de 2,9\% da área urbana entre 1988 - 2013 (2,7\% para 5,6\%).

Concomitantemente, as mudanças morfológicas no período evidenciam a manutenção de medidas corretivas direcionadas a adaptação das rupturas topográficas à área urbana deste 
local. Neste intervalo de tempo, a redução na quantia de rupturas (4 em 1988 para 2 em 2013) advinda do distanciamento, acrescido da junção de trechos dessas resultou no aplainamento do relevo.

O estabelecimento da mencionada morfologia antropogênica proveniente de intervenções nas rupturas topográficas realizadas na expansão da área urbanizada no período de 1978 a 2013 pode ser verificado na Figura 5.

O período de 1988 - 2009 foi caracterizado por uma retomada dos processos erosivos lineares, regida pelo aumento do número total e extensão de sulcos erosivos e manutenção das voçorocas (Figura 2A e 2B). As ravinas foram, novamente, identificadas com comportamento distinto, já que foram contidas no período. A contenção se desenvolveu em parcelas marcadas pela introdução da cana-de-açúcar e da silvicultura. Desta forma, acredita-se que o maquinário envolvido nesta mudança do uso da terra promoveu a obliteração dos canais das referidas ravinas.

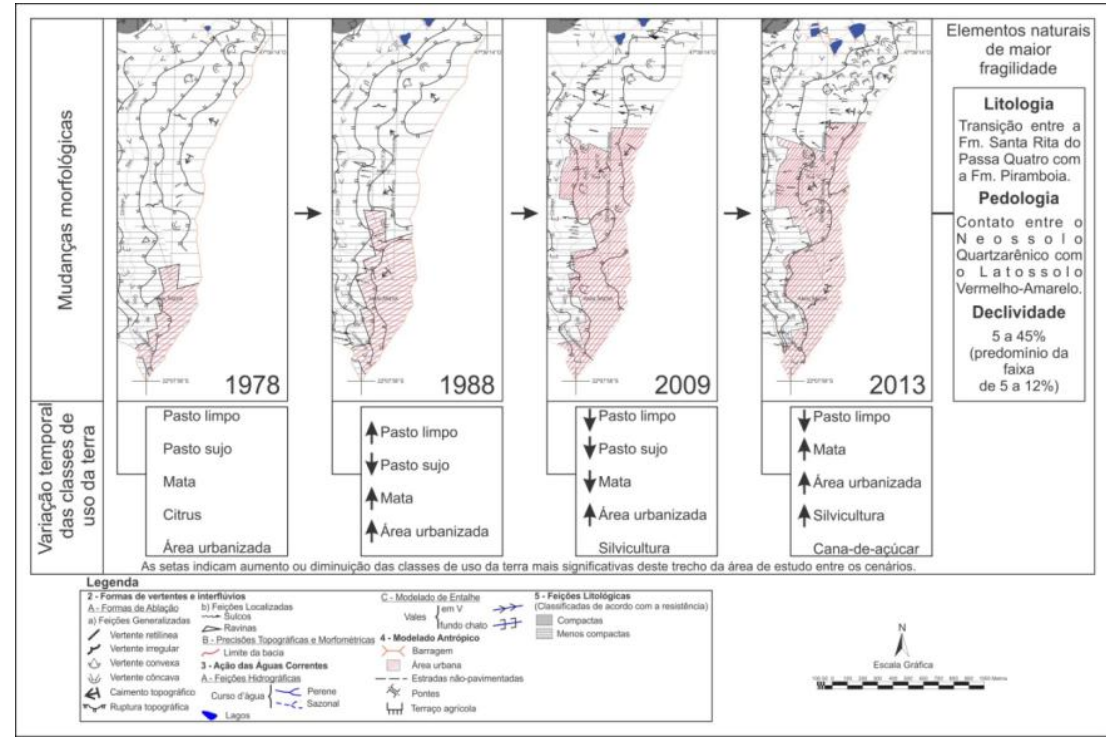

Figura 5: Constituição de morfologia antropogênica relacionada ao geoindicador rupturas topográficas decorrente da variação temporo-espacial da classe de uso da terra área urbanizada e demais classes significativas no sudeste da bacia do Córrego do Cavalheiro - Analândia (SP) no período de 1978 a 2013. Elaborado pelos autores (2015).

A queda expressiva nos valores dos geoindicadores leques aluviais (Figura $2 \mathrm{C}$ ) e rupturas (Figura 2E), ao lado da manutenção na quantia de colos topográficos (Figura 2D) sugere a redução da erosão laminar. 
A suposta inversão dos processos erosivos neste período pode estar diretamente relacionada com a diminuição de $5,3 \%$ da área coberta por matas $(18,4 \%$ para $13,1 \%)$ e ao surgimento de uma ocupação de 10,2\% de cana-de-açúcar (Gráfico 1). O uso de maquinário no plantio de cana-de-açúcar tende a obliterar os sulcos erosivos, porém esses passam a ser estabelecidos nos canais coletores que compõem os terraços agrícolas, caracterizados pela concentração do escoamento superficial.

É importante salientar ainda que a introdução da cana-de-açúcar pode justificar a mencionada diminuição na extensão das rupturas topográficas, já que este cultivo é comumente realizado por meio do plantio em curvas de nível, cuja técnica conservacionista de caráter mecânico possibilita a descaracterização e, muitas vezes, a eliminação desta feição geomorfológica.

Todavia, no período seguinte (2009 - 2013), verifica-se um aumento na extensão desta feição (Figura 2E), assim como no número total dos demais geoindicadores que fazem alusão a erosão laminar - leques aluviais e colos topográficos (Figura 2C e 2D).

A ampliação das rupturas topográficas foi acompanhada por expressiva constituição de terraços agrícolas, organizados na introdução da cana-de-açúcar em detrimento do pasto limpo. Neste viés, acredita-se que a longo prazo o tipo de manejo realizado por este cultivo dinamize o processo denudativo. Tal conjetura implica em maior liberação de sedimentos para o sistema fluvial, que pode resultar na perda de seu potencial de transporte, fornecendo as condições necessárias para a formação de leques aluviais.

O surgimento de um leque aluvial no período expressa tal contexto, porém a totalidade desta feição em 2013 (2) ainda é inexpressiva frente a possível dinamização da erosão laminar, situação que denota a possibilidade de saída do material deste sistema, iniciada entre os cenários de 1988 - 2009 quando foi constatada a queda em seu valor total (Figura 2C).

Além da retomada do referido processo denudativo, este período foi assinalado pela dinamização dos processos erosivos lineares, evidenciado pelo aumento do parâmetro quantidade das feições erosivas lineares (Figura 2A). Assim, o período 2009 - 2013 é distinguido pela justaposição de processos morfogenéticos que podem ser decorrentes da 
dinâmica do uso da terra, exposta no gráfico 1 pela ampliação do cultivo da cana-de-açúcar (10,2\% para $24,8 \%)$ e considerável redução na área da classe de uso da terra pasto limpo $(53,5 \%$ para $29,6 \%)$.

De forma geral, constatou-se que a evolução dos geoindicadores na série histórica estabelecida neste estudo respondeu diretamente a dinâmica do uso da terra, salvo as excepcionalidades advindas da influência dos elementos lito-pedológicos e clinográficos que compõem o sistema da bacia hidrográfica do Córrego do Cavalheiro.

\section{CONSIDERAÇÕES FINAIS}

A análise dos dados geomorfológicos e de uso da terra numa série histórica possibilitou a definição de geoindicadores e acompanhamento de seus novos arranjos, que permitiram quantificar as mudanças morfológicas induzidas pelas intervenções antrópicas advindas da evolução do uso da terra e, consequentemente, fornecer indícios sobre a gênese de uma morfologia antropogênica.

No caso específico da bacia do Córrego do Cavalheiro, os geoindicadores se mostraram eficazes no monitoramento de formas do relevo que indicam processos morfogenéticos dinamizados pela ação antropogênica no meio rural.

As feições erosivas lineares e as rupturas topográficas responderam de forma mais significativa às mudanças do uso da terra. O aumento das áreas identificadas com pasto limpo e mata no período 1962 - 1988 resultou no controle das feições erosivas lineares, demonstrando a amenização desse tipo de processo erosivo. Em contrapartida, tais usos não contiveram a ocorrência de processos denudativos nas áreas com fragilidade lito-pedológica, já que o aumento na extensão das rupturas topográficas sugere o desenvolvimento da erosão laminar.

A descaracterização das rupturas topográficas no cenário de 2009 e a maior expressividade das feições erosivas lineares convergem para a inversão dos referidos processos erosivos, sendo tal situação acompanhada pela introdução da cana-de-açúcar e a diminuição das áreas cobertas por mata e pasto limpo. 
O manejo agrícola realizado no cultivo da cana-de-açúcar em 2013 provocou a dinamização de ambos os processos morfogenéticos, evidenciada no aumento da quantia das feições erosivas lineares e geoindicadores relacionados a erosão laminar.

O comportamento distinto dos leques aluviais perante a constante variação dos processos denudativos mostra a sua considerável inexpressividade para a mensuração das intervenções de atividades agropecuárias em bacia hidrográfica de pequena extensão areal. A menor quantia deste geoindicador em momentos de maior aporte de sedimentos indica o possível aumento do gradiente erosivo sobre tais feições ou a saída do material deste sistema. Assim, acredita-se que o uso desse para uma representação mais efetiva aos controles impostos pela atividade antrópica nas feições e processos geomorfológicos associados deve ser realizado para sistemas ambientais de maior extensão areal e, em conjunto com outras fontes de dados que demonstrem a influência antropogênica na dinâmica deposicional.

De forma geral, os geoindicadores específicos deste estudo configuram um esforço inicial no desenvolvimento de uma proposta que auxilie em leituras quantitativas de morfologias em sistemas ambientais com dinâmica natural e uso da terra análoga a bacia do Córrego do Cavalheiro. É importante salientar que esta proposta se encontra aberta a introdução de novos parâmetros que considerem particularidades morfogenéticas nas mais distintas dimensões espaço-temporais.

Por fim, evidencia-se que a aplicação da metodologia dos geoindicadores contribui na obtenção de dados nos cenários em que a Antropogeomorfologia domina a esculturação do relevo, colaborando com estudos voltados ao planejamento ambiental, já que fornece subsídios na formulação de modelos que visam moderar, reverter e, até mesmo estimar cenários futuros de sistemas ambientais que se encontram sob intervenção antrópica.

\section{AGRADECIMENTOS}

À Fundação de Amparo à Pesquisa do Estado de São Paulo (FAPESP) - Processos no. 2012/20513-0 e 2013/15830-9, pelo financiamento das pesquisas. 


\section{BIBLIOGRAFIA}

BRASIL. Ministério do Desenvolvimento, Indústria e Comércio Exterior. Balança comercial brasileira: julho $2014 \quad-\quad$ 1a semana. Disponível em: <http://www.mdic.gov.br/sitio/interna/interna.php?area=5\&menu=567>. Acesso em: 9 jul. 2014.

CHRISTOFOLETTI, A. Análise de sistemas em Geografia. São Paulo: Hucitec, 1979.

COLTRINARI, L. Mudanças ambientais globais e geoindicadores. Pesquisas em Geociências, Porto Alegre, v. 28, n. 2, p. 307-314, maio/ago. 2002.

COLTRINARI, L.; McCALL, G. J. H. Geoindicadores: ciências da Terra e mudanças ambientais. Revista do Departamento de Geografia, São Paulo, v. 9, p. 5-11, 1995.

CUNHA, C. M. L. da; PINTON, L. de G. A cartografia das restrições legais ao uso da terra a partir de parâmetros da legislação ambiental. CLIMEP, Rio Claro, v. 4, n. 1, p. 29-52, jul./dez. 2009.

GOUDIE, A. Human influence in geomorphology. Geomorphology, v. 7, p. 37-59, 1993.

GUPTA, A. Geoindicators for tropical urbanization. Environmental Geology, v. 42, p. 736-742, 2002.

HAFF, P. K. Neogeomorphology, Prediction, and the Anthropic Landscape. Draft, Durham, p. $1-22,2001$.

KOEFFLER, N. F. et al. Solos da bacia do Rio Corumbataí. Rio Claro: Departamento de Cartografia e Análise da Informação Geográfica - Instituto de Geociências e Ciências Exatas, Universidade Estadual Paulista, 1992. Escala: 1: 50.000.

MELO, M. S. de. A Formação Rio Claro e depósitos associados: sedimentação Neocenozoica na depressão periférica paulista. 1995. 144 f. Tese (Doutorado em Geologia Sedimentar) Instituto de Geociências, Universidade de São Paulo, São Paulo, 1995.

MONTEIRO, C. A. de F. A dinâmica climática e as chuvas no Estado de São Paulo - estudo geográfico sob forma de atlas. São Paulo: Instituto de Geografia, Universidade de São Paulo, 1973.

NIR, D. Man, a geomorphological agent: an introduction to anthropic geomorphology. Jerusalem: Ktern Pub. House, 1983.

PINTON, L. de G. A antropogeomorfologia na bacia do Córrego do Cavalheiro - Analândia/SP: uma avaliação da dinâmica do uso da terra e sua adequabilidade a legislação ambiental e a capacidade de uso. 2011. 102 f. Trabalho de conclusão de curso (Bacharelado em Geografia) - Universidade Estadual Paulista, Rio Claro, 2011.

RODRIGUES, C. Avaliação do impacto humano da urbanização em sistemas hidrogeomorfológicos. Desenvolvimento e aplicação de metodologia na grande São Paulo. Revista do Departamento de Geografia, São Paulo, n. 20, p. 111-125, 2010.

RODRIGUES, C. Geomorfologia Aplicada: avaliação de experiências e de instrumentos de planejamento físico-territorial e ambiental brasileiros. 1997. 299f. Tese (Doutorado em 
Geografia Física) - Faculdade de Filosofia, Letras e Ciências Humanas, Universidade de São Paulo, São Paulo, 1997.

RODRIGUES, C. Morfologia original e morfologia antropogênica na definição de unidades espaciais de planejamento urbano: exemplo na metrópole paulista. Revista do Departamento de Geografia, São Paulo, n. 17, p. 101 - 111, 2005.

SÃO PAULO (Estado). Secretaria de Agricultura e Abastecimento. Coordenadoria da Pesquisa de Recursos Naturais. Folha Geológica de Corumbataí (Folha SF-23-Y-A-I-2): Formações Geológicas de Superfície. São Paulo: Instituto Geológico, 1984. Escala 1:50.000.

SZABÓ, J. Anthropogenic geomorphology: subject and system. In: SZABÓ, J; DÁVID, L.; LÓCZY, D. (Org.). Anthropogenic geomorphology: a guide to man-made landforms. New York: Springer, 2010.

TRICART, J. Principes et méthodes de la géomorphologie. Paris: Masson, 1965.

VERSTAPPEN, H. T.; ZUIDAN, R. A. van. ITC System of geomorphological survey: manual ITC textbook. Enschede, Netherlands, 1975.

\begin{tabular}{|r|r|}
$\begin{array}{r}\text { Artigo submetido em } \\
\text { Artigo aceito em }\end{array}$ 26/09/2014 \\
\hline
\end{tabular}

